\title{
Inquisição ao avesso: a trajetória de um inquisidor a partir dos registros da Visitação ao Tribunal de Goa
}

\author{
Célia Cristina da Silva Tavares
}

Considerada um gênero menor por boa parte dos historiadores do século XX, a biografia tem sido recuperada nos últimos anos em termos mais complexos do que apenas registrar os momentos relevantes da vida de um destacado indivíduo. Percebe-se que há uma crescente produção nesta linha ao se realizar um estudo sobre o tema.

Lucien Febvre proferiu uma conferência intitulada "Erasmo e sua época" em agosto de 1949 no Rio de Janeiro, na Academia Brasileira de Letras. ${ }^{1}$ Nela o autor apresentou vários perfis, destacando inclusive características físicas de personagens históricos conhecidos. Apontou que Carlos de Habsburgo tinha a mandíbula prognata; que Henrique VIII era gordo, sanguíneo e violento; que Francisco Valois era narigudo. Quando se concentrou em Erasmo, o homem que o historiador francês desenhou com palavras era pequeno, frágil, delgado, sempre se queixando de sua saúde. ${ }^{2}$ Mas o fundador dos Annales não se restringiu a essas pinceladas rápidas. Em outros artigos publicados no mesmo volume onde se encontra este que se refere à visita do grande historiador ao Brasil, percebe-se que ele procurou olhar para o humanista do século XVI por quadros esboçados por outros autores. Apresenta Erasmo a partir de alguns de seus biógrafos: Augustin Renaudet, Johan Huinzinga e Marcel Bataillon. Analisando essas biografias, Lucien Febvre tenta mostrar vários ângulos da figura histórica estudada, ${ }^{3}$ numa curiosa e estimulante abordagem, que mistura a trajetória de vida dessa personagem, assim como a construção das biografias a partir das preocupações que povoavam as mentes dos biógrafos citados.

Segundo Jacques Le Goff, na introdução da sua biografia sobre São Luís, houve "um eclipse da biografia histórica no coração do século XX" ${ }^{4}$ Certamente porque ela era considerada como "o modelo de história tradicional, mais sensível à cronologia e aos grandes homens que às estruturas e às massas", 5 típica crítica dos Annales, o que torna mais curioso o esforço feito por Febvre ao apresentar a biografia de Erasmo, demonstrando que mesmo em momentos nos quais a biografia havia sido relegada a um segundo plano, ainda assim, os historiadores podiam procurar esse estilo como uma forma de análise do passado.

No entanto, já não se pode dizer que o estudo biográfico é algo que está em desuso, muito pelo contrário. Desde a década de 80 percebe-se a crescente importância da biografia para a produção historiográfica atual. E à medida que os estudos biográficos aumentaram em número, esse tipo de produção tem suscitado um debate muito salutar entre historiadores e cientistas sociais de disciplinas afins.

Há um consenso em se perceber que a procura pelo estudo biográfico acompanha uma crise geral de paradigmas nas ciências em geral, particularmente nas sociais. ${ }^{6}$ Os historiadores estariam cansados de não ver formas humanas nas estruturas definidas a partir de análises generalizantes e estariam buscando o estudo de indivíduos para dar consistência a essas estruturas. ${ }^{7}$

Também existe uma concordância em se perceber que há problemas vinculados a esse tipo de abordagem, nomeadamente uma tendência à simplificação e à crença em um modelo de racionalidade que não caberia a um personagem histórico, como salienta, por exemplo, Giovanni Levi, ${ }^{8}$ acatando parte da crítica desenvolvida por Pierre Bourdieu contra as biografias. ${ }^{9}$ Não obstante isso, há um tom de defesa das biografias nos principais textos de historiadores que se preocuparam em definir esse campo nos últimos tempos.

Para Le Goff, por exemplo, "a biografia confronta hoje o historiador com os problemas essenciais - porém clássicos - de seu ofício de um modo particularmente agudo e complexo. Faz isso, todavia, num registro a que frequentemente já não estamos habituados." 10 Já Giovanni Levi afirma que "recorre-se a ela para sublinhar a irredutibilidade dos indivíduos e de seus comportamentos a sistemas normativos gerais, levando em consideração a experiência vivida"; ou ainda "ela é vista como terreno ideal 
para provar a validade de hipóteses científicas concernentes às práticas e ao funcionamento efetivo das leis e das regras sociais". ${ }^{11}$

De maneira clara, José Mattoso define o que mais interessa aos historiadores num estudo em escala microscópica:

o itinerário de uma pessoa ou de uma família, a análise da história e das instituições de uma pequena aldeia, a investigação de um acontecimento determinado. Note-se que, ao contrário do que acontecia outrora, nas bibliografias e monografias, não interessa tanto o caso, a pessoa ou o facto em si mesmos, mas a sua representatividade e a maneira como nele se repercutem as estruturas e os movimentos globais. Sendo assim, o que importa é a sua relação com o conjunto em que se insere e que ele exprime de uma maneira privilegiada. Por meio dele, o conjunto aparece, então, sob a sua forma histórica, situado no tempo e no espaço e objectivado em indivíduos concretos. Ultrapassam-se as abstrações. ${ }^{12}$

Deve-se ressaltar que Giovanni Levi apresenta uma tipologia de biografias ${ }^{13}$ que não se esgotariam na fórmula apresentada acima por Mattoso. Mas ao final, Levi faz o destaque aos pontos que merecem a atenção dos historiadores, que em certa medida complementa a reflexão do historiador português. Seria perceber "a relação entre normas e práticas, entre indivíduos e grupo, entre determinismo e liberdade, ou ainda entre racionalidade absoluta e racionalidade limitada", tendo consciência que "a biografia é por isso mesmo o campo ideal para verificar o caráter intersticial - e todavia importante - da liberdade de que dispóem os agentes para observar como funcionam concretamente os sistemas normativos, que jamais estão isentos de contradição". ${ }^{14}$

Por outro lado, Carlo Ginzburg sugere que o nome serve como o fio condutor de Ariadne no labirinto documental em que muitas vezes o historiador se vê enredado. ${ }^{15}$ Essa imagem já foi utilizada por outros historiadores que sabem que, por vezes, um nome proporciona uma viagem de exploração a aspectos ainda pouco estudados pela produção historiográfica. ${ }^{16}$

Ao longo da pesquisa por mim realizada para desenvolver a tese de doutorado - um estudo sobre a cristianização de Goa através da ação da Companhia de Jesus e da Inquisição, nos séculos XVI e XVII - um nome acabou destacando-se, o de João Delgado Figueira, licenciado que foi promotor do Tribunal de Goa, ${ }^{17}$ alcançou o cargo de inquisidor do Tribunal do Oriente e, de volta ao reino, foi inquisidor do Tribunal de Évora, depois do de Lisboa e, por último, passou a ser promotor deste mesmo tribunal, pois fora nomeado conselheiro letrado do recém-criado Conselho Ultramarino. ${ }^{18}$ Pela etiqueta acadêmica dos historiadores, eu devia colocar as datas que marcam cada um desses eventos registrados sobre a trajetória funcional de João Delgado Figueira, no entanto, por serem elas bastante confusas e gerarem alguma polêmica, decidi por enquanto apenas ressaltar os postos assumidos por esta personagem.

É importante que se diga que estudar o tribunal do Santo Ofício de Goa é uma tarefa muito difícil, uma vez que a maior parte das fontes referentes a essa instituição foi provavelmente destruída ${ }^{19}$ e o que sobreviveu é um material fragmentado e disperso em pelo menos quatro arquivos por mim visitados: a Biblioteca Nacional do Rio de Janeiro, a Biblioteca Nacional de Lisboa, a Biblioteca da Ajuda e o Arquivo Nacional da Torre do Tombo.

Logo no início da pesquisa de doutorado, quando fazia o levantamento das fontes, deparei-me com o nome de João Delgado Figueira, uma vez que ele figurava no acervo da seção de reservados da Biblioteca Nacional de Lisboa como autor de um importante repertório de sentenciados pelo Tribunal do Santo Ofício de Goa. ${ }^{20}$ Esse tipo de organização dos culpados era recomendado pelo regimento da Inquisição, no entanto, até então não havia sido organizado em Goa, o que indica uma postura muito disciplinada do promotor João Delgado Figueira e que foi ressaltada na correspondência dos inquisidores de Goa com o Conselho Geral da Inquisição em Lisboa, como veremos adiante.

À medida que avançava por outros documentos em outras instituiçôes de pesquisa, reencontrava o mesmo nome: cartas ao inquisidor-geral, cartas trocadas com o vice-rei da Índia, tratados sofisticados sobre questôes doutrinais, desenvolvimento de investigaçôes e por fim alvo de uma visitação feita ao 
Santo Ofício de Goa. Por tudo isso, ficou claro que se tratava de um personagem-chave para a compreensão do funcionamento da Inquisição no Estado da Índia, o meu fio de Ariadne naquele labirinto de fontes no qual me aventurava.

Segundo Francisco Bethencourt, no caso dos cargos inquisitoriais, havia uma tendência comum na Inquisição ibérica de promoção restrita ao espaço colonial, quer dizer, a carreira do inquisidor no Oriente não era uma forma de ascensão para outros cargos eclesiásticos no reino, em geral. Bethencourt destaca que "a carreira dos inquisidores no tribunal de Goa é limitada, na maior parte dos casos, aos postos eclesiásticos nas Índias Orientais". ${ }^{21}$ Naturalmente houve exceções, como, no século XVI, a exemplo de "Bartolomeu da Fonseca, designado sucessivamente, depois de seu regresso de Goa, inquisidor de Lisboa (1583), inquisidor em Coimbra (1587), membro do Conselho Geral (1598), conselheiro real e agente da Inquisição portuguesa na corte de Filipe III" ${ }^{22}$ Para o século XVII, há o caso de João Delgado Figueira, que voltou para o reino depois da longa permanência em Goa, sendo designado inquisidor primeiramente do Tribunal de Évora em 1635, e depois da Inquisição de Lisboa, em 1641, e por último promotor desse tribunal, por ter sido nomeado conselheiro letrado do Conselho Ultramarino, em 1643, como dito anteriormente. ${ }^{23} \mathrm{E}$ as datas aqui são finalmente reveladas por serem estas as que foram assentadas de maneira mais sistemática pelas fontes inquisitoriais. ${ }^{24}$

Os cargos de deputados e promotores ${ }^{25}$ do Santo Ofício de Goa eram frequentemente ocupados por clérigos das ordens religiosas instaladas na capital do Estado da Índia, principalmente dominicanos e jesuítas. Mas havia também a possibilidade desses quadros terem origem no próprio reino e não estarem vinculados a essas ordens religiosas. ${ }^{26}$ Um bom exemplo disso é, mais uma vez, o próprio João Delgado Figueira que, antes de atingir o cargo de inquisidor de Goa, fora nomeado como promotor da Inquisição oriental. ${ }^{27}$

Entretanto, as fontes inquisitoriais calam-se sobre a formação deste funcionário e muitas vezes são confusas sobre a sua trajetória. Antônio Baião sublinha que não foi possível encontrar o processo de habilitação de João Delgado Figueira que daria informações precisas de nascimento, filiação e formação, como temos para quase todos os inquisidores estudados por este autor. ${ }^{28}$ De fato, não há o menor vestígio deste documento até onde pudemos investigar na Torre do Tombo. Conseguimos informações indiretas de genealogia que atribuem o batismo de João Delgado Figueira ao dia 2 de setembro de 1585, em Ourém, sendo filho de Brás Figueira e Brites Delgada, mas é dado que necessita de maior pesquisa para confirmação, assim como o dia e ano de sua morte: 16 de maio de 1654 .

O pior para se definir a biografia desta figura de importância singular para o estudo da Inquisição de Goa é não obtermos nenhuma informação sobre sua formação. Sabemos apenas que ele é o licenciado João Delgado Figueira que, em carta de 15 de março de 1616, foi apresentado e recomendado pelo Conselho Geral da seguinte forma aos inquisidores de Goa:

chegado lá a salvamento [o promotor Delgado Figueira] V. Ms. o recebam e tratem como ele por sua pessoa merece; é pessoa de que temos muito boa informação assim de sua virtude, letras e talento que esperamos que com os bons ofícios V. M.s lhe farão, dará de si um grande ministro. ${ }^{29}$

Em outra carta, do ano seguinte, obtém-se a informação de sua maior atribuição:

o reportório que V. Ms. pedem para reportarem os culpados dessa inquisição mandei fazer e o leva João Delgado Figueira que hora vai por promotor desse Santo Oficio que tornou a arribar o ano passado a este reino. Encomendo a V. Ms. o recebam e tratem como ele merece por sua pessoa, letras e partes. E serviulhe este naufrágio para levar experiência das coisas do Santo Oficio como leva por assistir no secreto desta Inquisição de Lisboa todo o tempo que lhe vagou. ${ }^{30}$

Sabe-se também por este trecho citado acima que a viagem de ida de João Delgado Figueira foi muito atribulada. Sofreu um naufrágio, como é informado, voltou ao reino e só chegou a Goa em 30 de janeiro de $1618 .{ }^{31}$ 
Como promotor e deputado do Santo Ofício de Goa foi o responsável pela publicação em 1624 do já citado repertório dos sentenciados da Inquisição oriental, algo que havia sido recomendado regimentalmente, mas que nunca fora cumprido até então, o que indica zelo e obediência por parte desse funcionário da Inquisição.

Aparentemente foi a primeira tarefa a que se dedicou e pela qual colecionou uma série de elogios dos inquisidores em cartas consecutivas entre os anos de 1619 - "por ter posto em muita ordem as coisas do Secreto" - e 1621 - "vendo com muito trabalho todos os processos que se tem despachado os relatou brevemente e pôs em tal ordem que facilmente todo o ministro deste Santo Ofício se poderá inteirar deles" ${ }^{\prime 2}$ - que repercute de maneira da mesma forma elogiosa por parte do Conselho Geral, que manda carta em 3 de março de 1622 com os seguintes dizeres:

ao Licenciado João Delgado Figueira, promotor e deputado dessa Inquisição agradeço muito o bom cuidado que tem de cumprir com as obrigações com tanta satisfação como V. Ms. me escrevem e eu sei por outras vias e em particular lhe agradeço o trabalho que teve em ordenar o Secreto dessa Inquisição como vi e esteja certo que me não esquecerei de seus serviços para os lembrar a S. M. de como tenho feito e faço. ${ }^{33}$

Em outra carta do mesmo ano, o inquisidor-geral afirma que "muito estimei o livro que fez o promotor João Delgado Figueira; não me esquecerei de lhe procurar os acrescentamentos e mercês que merece". ${ }^{34}$

Tanto Antônio Baião como José Alberto Rodrigues da Silva Tavim concordam que todo esse esforço de organização arquivísitca "era o trilho aberto para o cargo de inquisidor, através do zelo da eficiência". ${ }^{35}$ De fato, isso poderia contar, ainda mais com outros serviços associados que o promotor desempenhou, como o do exemplo detalhado a seguir.

É também de sua autoria o documento enviado à Santa Sé, em 1619, contra os ritos gentílicos e as práticas defendidos pelo jesuíta Roberto de Nobili. ${ }^{36}$ Da mesma forma, participou de uma junta de teólogos formada pelo governador Fernão de Albuquerque, na qual se discutiu os ritos gentílicos e de onde resultou a decisão de se proibirem as festas de casamentos dos hindus em Goa, através do alvará de 31 de janeiro de 1620. Este ponto é muito polêmico e merece ser mais detalhado.

Portanto, logo no início de suas atividades como promotor João Delgado Figueira foi protagonista de um atrito entre a Inquisição de Goa e a Companhia de Jesus. O centro da questão era a discussão sobre os ritos gentílicos defendidos pelo padre Roberto Nobili como sinais exteriores e inofensivos à fé católica, o que havia levantado muitas suspeitas sobre a validade das conversóes realizadas por esse jesuíta no Malabar. ${ }^{37}$

Os debates já se desenvolviam acalorados desde 1610, quando em 1618, o papa Paulo V ordenou que o arcebispo e os inquisidores de Goa fizessem uma junta para analisar as práticas do jesuíta italiano no Malabar. Em 31 de janeiro de 1619 foi instalada a comissão formada pelos arcebispos de Goa e Cranganor e pelo promotor da Inquisição, João Delgado Figueira. O propósito da junta era tomar "perfeita informação se os ritos dos brâmanes e a linha e o sendi e o sândalo e uso de lavatórios são sinais da falsa seita dos ídolos". ${ }^{38}$

O primeiro registro dos trabalhos da junta refere-se ao arcebispo de Cranganor, que apresentou à junta um "tratado comprido" sobre a natureza dos ritos gentílicos, recomendando que fosse lido por teólogos. Além disso, havia livros trazidos de Maduré, mas que só ele e o padre Nobili saberiam ler. O arcebispo de Goa solicitou então que eles lhes contassem o que havia nos livros. O jesuíta italiano foi o primeiro a falar, e defendeu o caráter político dos ritos gentílicos. ${ }^{39}$

No dia 9 de fevereiro de 1619 o arcebispo de Cranganor enviou uma carta à junta, onde declarou que ele e os padres da Companhia de Jesus sabiam "de vista e experiência de muitos anos e da lição dos livros e línguas dos brâmanes" que a linha, o sândalo e os lavatórios eram sinais da nobreza das famílias brâmanes, fazendo forte defesa de Nobili. ${ }^{40}$

Entretanto, havia quem discordasse. Uma carta do bispo de Cochim, datada de 6 de junho de 1619, usa o mesmo argumento da experiência para denunciar de forma veemente os ritos gentílicos, ao afir- 
mar que: "Há trinta e cinco anos e seis meses que vim para a Índia [...] e pela experiência que tenho destas partes [...] tenho sabido que a linha é sinal demonstrativo de gentilidade e de religião falsa que os brâmanes gentios professam." ${ }^{41}$

João Delgado Figueira articulou seus trabalhos apresentando primeiramente um arrazoado sobre a questão, enumerando as dúvidas enviadas pelo papa e depois contrapondo argumentos contra e a favor dos ritos gentílicos. Desdobrou as dúvidas em dois níveis: "se é lícito" e "se é necessário" o uso dos ritos gentílicos. Afirmou logo a princípio que não era lícito, sem mais delongas, por serem evidências de ligação com a religião dos gentios, mas dedicou-se em seguida à análise minuciosa da necessidade da permissão do uso dos ritos para o bem da conversão. Concluiu dizendo que: "Os ditos sinais protestativos da gentilidade oriental são sinais muito pertencentes à religião dos ditos pagodes e não se convém que se permitam na Cristandade", enfatizando o caráter diabólico dessas manifestações. ${ }^{42}$ Trata-se de um texto elegante, extremamente erudito, que demonstra o grande conhecimento da realidade indiana que tinha João Delgado. Além desse parecer, ou voto - que ficou nos registros da Inquisição -, elaborou ainda um parecer em latim, datado de 10 de abril de 1619, com cópias despachadas para Roma e para o Conselho Geral do Santo Ofício em Lisboa; são oitenta e seis folhas nas quais o promotor desenvolve as ideias já expostas. ${ }^{43}$

No entanto, João Delgado Figueira não se restringiu à construção de uma argumentação contra os ritos gentílicos, mantendo sua atenção para a questão. Em 1620 recebeu um texto de cinco padres brâmanes, vigários de igrejas de Goa, que afirmavam "ser a linha e curumbim sinal de seita". Nele os clérigos seculares nativos explicavam que:

a linha de que é a questão, ordinariamente se faz de nove fios porque têm os brâmanes para si, e de opinião que corre entre eles, que o mundo se reparte em nove partes, e desses nove fios se fazem três cordéis delgados, os quais lançam ao tiracolo do ombro esquerdo ao modo de colar como um só. Estes três cordéis em protestação dessa divindade falsa que adoram, tem um só nó porque dizem que estas três falsas pessoas são Brama, Visnnú, Mtayesou; compondo de nove fios para mostrar que todas as criaturas destas nove partes do mundo estão sujeitas a estes falsos deuses que adoram. ${ }^{44}$

Relataram ainda que a linha era posta pelo sacerdote hindu, o boto, o que implicava necessariamente frequentar uma série de cerimônias gentílicas. Por fim, desautorizaram completamente a interpretação defendida por Nobili e pelo arcebispo de Cranganor, e alertaram para "o perigo de escândalo para a Cristandade". Após esse episódio, no mesmo ano, João Delgado Figueira fez uma convocação para se apresentarem à Inquisição vários portugueses, civis (11) e religiosos (2), que habitavam por longo tempo a cidade de Goa, e a clérigos seculares nativos (7) de várias paróquias da cidade e adjacências (inclusive Bardez e Salcete). Para todos fez a mesma pergunta: "se sabiam o significado da linha". Todos responderam que sim, e todos, sem exceção, disseram que ela era um sinal de seita gentílica. Não é difícil perceber o objetivo do promotor: trata-se da construção de um argumento bem alicerçado para defender a objeção aos métodos de cristianização de Nobili, destacando a possibilidade de escândalo que a permissão do uso dos ritos gentílicos podia causar à cristandade sitiada da capital. ${ }^{45} \mathrm{Ou}$ seja, mais uma vez, é possível ver um arguto e disciplinado funcionário da Inquisição de Goa em ação e com certeza, junto com o trabalho de organização do Secreto daquele tribunal, ele reunia todos os requisitos para se tornar um inquisidor.

Foi o que ocorreu, mas, curiosamente, de forma que não era propriamente a usual. Com a morte do inquisidor João Fernandes de Almeida, em 5 de novembro de 1624, João Delgado Figueira tornou-se inquisidor junto a Francisco Borges de Sousa, pois já assinava o relatório anual junto com este último, em 17 de fevereiro de 1625. A novidade aí foi a maneira pela qual chegou ao cargo. O próprio Figueira alegou possuir uma provisão que tinha sido dada pelo inquisidor-geral, Fernão Martins Mascarenhas, para que ele entrasse no primeiro lugar que vagasse no tribunal oriental. Baseados nisso, os dois inquisidores sequer fizeram comunicação formal ao vice-rei, o que causou grande mal-estar, a ponto do vice-rei solicitar a presença dos dois para esclarecimentos, inaugurando uma série de conflitos que vão acompanhar as ações do inquisidor Figueira. 
Além disso, parece que os traços de personalidade de João Delgado Figueira frequentemente o colocavam em situações de tensão e disputas. Mais um exemplo de conflito pode ser detectado em episódio ocorrido em Goa, quando um fidalgo assassinara outro em 23 de maio de 1629 por questóes de adultério. $\mathrm{O}$ assassino, d. Julianes de Noronha, escondeu-se na casa do inquisidor mais antigo na época, justamente João Delgado Figueira, que ficava contígua aos cárceres secretos da Inquisição. Ao saber disso, o ouvidor-geral do crime, Paulo Rabello, dirigiu-se imediatamente para lá, e "com todas as justiças levando escadas e machados as casas em que estava e abrira as barras por força e sem respeito ao lugar", procurou o criminoso "abrindo todas as portas em que podia haver perigo tirara o homiziado, excedendo em tudo o modo que então se tinha na Índia em semelhantes casos". ${ }^{46}$

Tratava-se na verdade de um grave desrespeito à autoridade do Santo Ofício, que certamente arranhava a imagem do tribunal na cidade. Dessa forma, o Conselho Geral respondeu à consulta do inquisidor João Delgado Figueira com a recomendação de que as demais autoridades de Goa respeitassem a Inquisição, enviando solicitação ao rei para que ele demonstrasse o seu descontentamento com o ocorrido.

Outro ponto de atrito ocorreu na questão do uso do palanquim, e mais uma vez colocou em rota de choque o inquisidor Figueira e um vice-rei da Índia. O uso desse meio de transporte estava largamente disseminado até finais do século XVI, quando se iniciou um processo de restrição de sua utilização. Catarina Madeira Santos informa que:

já em 1597, limitava-se o uso dos palanquins aos capitães das fortalezas, vedores da fazenda, secretário de Estado, ouvidor geral do crime, desembargadores e ouvidor da cidade. E, mais tarde, em 1615, proibia-se radicalmente o uso de palanquins na Índia, sem expressa licença do vice-rei. ${ }^{47}$

Mais tarde, em 1630, o vice-rei Conde de Linhares tinha mandado executar uma lei que proibia o uso do palanquim, exceto pelo arcebispo que já estava velho e doente, o que aborreceu os inquisidores, desejosos de manter esse privilégio. Estes pediram a intervenção do Conselho Geral do Santo Ofício que, de Lisboa, solicitou ao vice-rei que permitisse o uso de palanquim aos inquisidores. A resposta do Conde de Linhares ao Conselho Geral é uma pérola de desacato ao Santo Ofício, alegando que o rei:

tinha mandado com muito fundadas razões que não andasse nenhum homem em braços de outros, porque desta delícia nascera afeminarem-se os homens e que na Índia havia muitas mulas que os Inquisidores de Portugal andam nelas que assim podiam fazer o mesmo, ou inventar [?] carretas com cavalos em que andassem. ${ }^{48}$

A mesa do Conselho Geral do Santo Ofício solicitou ao rei que fizesse o vice-rei voltar atrás.

A correspondência entre o Conde de Linhares e o inquisidor João Delgado Figueira exemplifica até que ponto chegaram os atritos. No dia 10 de março de 1630 o vice-rei enviou uma carta ao inquisidor onde reclamava que este havia faltado ao "negócio do serviço de Sua Majestade", marcado pelo conde, solicitando, ao fim da missiva, uma resposta ao pé da carta. João Delgado Figueira respondeu conforme solicitado:

por V. Exa . me manda que responda ao pé desta o faço, e nela me manda dar razão porque me escusei de ir a uma junta que V. Ex ${ }^{a}$. faz de todos os ministros deste Estado, prelados maiores e inferiores das religióes [...]. Primeiramente digo que no serviço de S. Majestade não falho um ponto, e este ano com estar só neste Santo Ofício por não poder acudir a todas as diligências que se me cometeram do serviço [...]; além de estar tão maltratado que me não posso bolir e estar há 4 meses em casa sem poder ir aos ofícios divinos por $\mathrm{V}$. Ex $x^{\mathrm{a}}$. me proibir andar em uma cadeira como andam muito dos ministros Inquisidores e não Inquisidores em Portugal que não são tão enfermos como eu e não ter outra coisa em que andar e ser caluniado e mal aceito do pouco andar a pé $\left[\ldots . .{ }^{49}\right.$

Concluiu afirmando que devia toda obediência ao vice-rei, mas que sua alegação justificava sua falta; em uma última provocação, disse ter faltado outras vezes, e que o conde de Linhares não tinha feito tanto caso.

No dia seguinte, visivelmente irritado, o vice-rei voltou a solicitar uma resposta de João Delgado Figueira na mesma folha, abaixo do registro do inquisidor, acrescentando que sua proibição do uso da cadeira não era pessoal e sim genérica. Reconheceu que havia um inquisidor em Lisboa que a utiliza- 
va, mas este tinha que vencer ladeiras muito dificultosas, enquanto o percurso que Figueira tinha que percorrer em Goa era muito mais fácil. Afirmou, por último, que já havia oferecido a ele dinheiro para comprar uma mula. João Delgado Figueira responde, dessa vez secamente, dizendo que "se queira dar por satisfeito com eu dizer de mim que nem pude e nem posso mais pelas razões de minhas indisposições e as mais que tenho dado"..$^{50}$ Fica claro que o inquisidor entendia que a proibição do uso do palanquim era um desrespeito à condição de seu cargo, apesar das alegadas justificativas de saúde. Por fim, o Conselho Geral do Santo Ofício despachou em favor do inquisidor de Goa. ${ }^{51}$ Tavim alerta para um dado adicional ao informar que a origem da rivalidade entre João Delgado Figueira e o conde de Linhares teria sido o fato dos inquisidores terem absolvido Francisco de Melo e Castro, capitão-mor das naus que o vice-rei tinha mandado prender no tronco. ${ }^{52}$

O empenho de João Delgado Figueira em desautorizar os métodos de cristianização de Nobili no Malabar, no tempo em que era promotor, e o estilo de confronto com os vice-reis e demais autoridades do Estado da Índia, já como no cargo de inquisidor devem ter angariado muitas antipatias contra Figueira, o que talvez expliquem ou, até mesmo, sejam as razões preponderantes para que tenha sido organizada uma visitação à Inquisição de Goa, em 1632, na altura em que Figueira já era então o primeiro inquisidor do Tribunal de Goa.

Há notícias de visitações ao tribunal de Goa em 1583, 1591, 1608 e 1632. Sobre as três primeiras não existem muitas informações, exceto o nome dos visitadores: frei Gaspar de Melo, padre Pedro Martins, bispo do Japão e o arcebispo d. Aleixo, respectivamente. Já para a visita de 1632 existe uma documentação consistente e muito rica. ${ }^{53} \mathrm{O}$ inquisidor-geral, d. Francisco de Castro, estabeleceu a visitação, constituindo como visitador Antônio de Vasconcelos, inquisidor de Lisboa, cavaleiro da casa real. O secretário das sessões era o provincial da Companhia de Jesus na Índia, o padre Antônio de Andrade. ${ }^{54} \mathrm{O}$ maior alvo dessa visitação foi o inquisidor João Delgado Figueira, contra quem pesaram muitas e graves acusações, das quais destacam-se:

[...] ele costuma se ausentar do Tribunal, deixando só o tribunal de 12 a 15 dias [...] que ele não permitia que se guardasse o Regimento, entre outros abusos. [...] Com todos os vice-reis de seu tempo teve quebras e pôs em risco por isso a Inquisição. [...] Sempre teve pouca paz com os inquisidores seus companheiros e superiores. [...] Teve trato com gente da costa da Pimenta. ${ }^{55}$

Contra o segundo inquisidor, Antônio de Faria, não foram registradas culpas, mas outros funcionários também foram atacados. Os notários Mateus Gomes e Ângelo Monteiro sofreram acusações, entre outras, a de quebrarem o segredo do Santo Ofício. Familiares também foram acusados de abusos, assim como outros funcionários foram indiciados por se ausentarem das funçōes, particularmente o porteiro, o alcaide e o meirinho.

No processo de investigação (o inquérito prolongou-se de 29 de outubro de 1632 até 7 de fevereiro de 1633) o visitador ouviu várias testemunhas. Uma das primeiras foi o próprio inquisidor acusado, que se calou na maioria das perguntas. Nas poucas vezes em que falou, fez graves acusações ao meirinho Luís Cardoso e ao notário Mateus Gomes, dizendo que tinham maus procedimentos para serem funcionários do Santo Ofício. Defendeu-se da acusação de estar muito ausente, o que propiciava fraudes sobre os pertences dos presos, dizendo que:

os presos naturais da terra de ordinário são muito pobres, algumas vezes acontece trazê-los o alcaide até estar presente o notário e depois lhe dá conta do que achou ao dito preso, entregando-lhe juntamente o que lhe achou. No que não pode haver fraude alguma porquanto depois se pergunta aos ditos presos e se lhe dá satisfação. ${ }^{56}$

Outro a ser ouvido foi o inquisidor Antônio de Faria que:

disse que tem ao Inquisidor João Delgado, por pessoa incapaz de servir ao Santo Ofício [...] por sua má natureza contumácia e descabimento que tem com as pessoas que servem em sua companhia ao Santo Ofício. [...] o dito João Delgado é parcial e respectivo que havendo concordado com ele testemunha que servisse o 
cargo de Deputado desta Inquisição o padre Antônio de Andrade provincial da Companhia e sucedeu de ser o dito religioso juiz na segunda instância de uma causa do doutor Paulo Rebelo e votando o que entendia, acertou de ser contra o voto de João Delgado depois do que haverá cinco ou seis meses sucedeu sendo necessário perfazer o número de cinco votos na mesa desta Inquisição, digo sendo necessário para o dito [...] chamar-se o dito religioso Antônio de Andrade, disse ele testemunha ao dito João Delgado que o elegesse deputado, conforme entre ambos se tinha resolvido. Ao que o dito João Delgado respondeu havia para isso inconveniente, o qual era que o dito religioso havia sido parte em uma coisa que havia entre alguns padres da Companhia e do Santo Ofício. ${ }^{57}$

Depreende-se do testemunho do inquisidor que havia grave conflito entre o provincial da Companhia de Jesus e o inquisidor João Delgado Figueira. Mas o que poderia ser definido como rusga entre os inquisidores, na verdade, assume o peso e gravidade de acusações vindas de outras pessoas. Frei Diogo de Santa Ana, que era o deputado do Santo Ofício mais antigo naquela altura, provincial da Ordem de São Francisco, também o acusou de negligente nas suas funções, pois não assistia às sessões de tormento. Outro franciscano, frei João de Abrantes, declarou que ele não tinha talento nem capacidade para exercer o cargo. O jesuíta José Álvaro Tavares, reitor do Colégio de São Paulo e deputado do Santo Ofício, reafirmou a incompetência de João Delgado Figueira dizendo que "não tem a paz e concórdia que se requer". ${ }^{8}$ Ou seja, havia um consenso em considerar João Delgado Figueira um inquisidor que não cumpria suas obrigações regimentais e, muito pior, era useiro em criar instabilidade da cristandade na Índia.

Francisco Bethencourt resume assim os registros dos interrogatórios:

João Delgado Figueira é acusado de mais de cem infrações, nomeadamente de abuso de poder para com os presos e para com os funcionários, de retirar indevidamente dinheiro do fisco, de possuir documentos secretos do tribunal em sua casa, de prender arbitrariamente inimigos pessoais, de provocar conflitos constantes com autoridades civis e de interferir nas eleiçōes dos provinciais das ordens religiosas. A concentração de acusações no primeiro inquisidor revela-nos um caso significativo de uma rede de clientelismo em que estão envolvidos cristãos-novos e religiosos. ${ }^{59}$

A maior parte das acusações foi confirmada pelo próprio visitador que encaminhou o interrogatório para o Conselho Geral do Santo Ofício.

Portanto, se as acusaçōes eram verdadeiras ou se foram resultado de manobras de caráter político, não se pode precisar, mas com certeza João Delgado Figueira era um homem que não estava afinado com as visões dos jesuítas e tinha um histórico de rusgas muito graves com altas autoridades civis. ${ }^{60}$

Sabe-se que, após esse episódio da visitação, João Delgado Figueira foi obrigado a voltar para o reino (o que o próprio inquisidor já havia solicitado em carta de 1630 na qual alegava "que se lhe devia a reedificação do Santo Ofício, queixava-se da falta de dinheiro para se sustentar e desejava voltar ao reino", ${ }^{61}$ ou seja, não foi propriamente uma punição), onde assumiu diversos cargos de destaque na Inquisição e na estrutura administrativa do reino, como já dito anteriormente. É justamente por causa da brilhante carreira que percorreu após seu retorno a Portugal que se pode supor que, ao fim e ao cabo, ele não devia ser tão displicente funcionário como foi descrito pelo visitador. A própria presença como secretário dos trabalhos da visitação de um jesuíta do porte de Antônio de Andrade também alimenta a suspeita de que se tratava de uma espécie de revanche de alguns membros da Companhia de Jesus, em função da oposição cerrada que Delgado Figueira fizera às proposições de Roberto Nobili e até mesmo a sua rigidez diante das práticas gentílicas dos cristãos da terra, que devia marcar sua atitude diante desses crimes.

Apesar da importância crescente que se pode verificar em termos dos cargos que João Delgado Figueira foi obtendo no seu retorno ao reino, infelizmente não há correspondência de aumento de informaçōes colhidas. O que se pode depreender das fontes é muito pouco. Sabemos que ele assumiu o cargo de inquisidor em Évora, em 31 de janeiro de 1635 (e ficamos sem nenhuma informação sobre ele desde 1633, apenas supondo o seu retorno que pode ter sido, mais uma vez, marcado por alguma viagem atribulada); seguindo ao cargo de inquisidor em Lisboa, em 25 de janeiro de 1641, para sabê-lo coloca- 
do como promotor deste mesmo tribunal, em 14 de dezembro de 1643, apenas porque havia galgado posto de maior prestígio, pois fora designado pelo próprio rei D. João IV, como membro do Conselho Ultramarino, na qualidade de conselheiro letrado.

No ato de fundação do Conselho Ultramarino pode-se ler o destaque que se deu a Figueira:

Pelo estado em que se acham as coisas da Índia, Brasil e Angola e mais conquistas do Reino, e pelo muito que importa conservar, e dilatar o que nelas possuo, e recuperar o que se perdeu em tempos passados, [...] resolvi a nomear Tribunal separado em que se particularmente tratem os negócios daquelas partes [...] e que este Tribunal [...] se chame Conselho Ultramarino, em que sirva de Presidente o Vedor da Fazenda da repartição da Índia e de secretário o Escrivão da Fazenda da mesma repartição [...] e dois Conselheiros de capa, e espada, e um letrado, pessoas que tenham serviços e notícias das Conquistas de tal satisfação que possa e deva esperar prudência, indústria, e trabalho conseguir o fim que pretendo, e por todas estas partes concorrerem nas pessoas de Jorge de Albuquerque, Jorge de Castilho e João Delgado Figueira Inquisidor Apostólico do distrito desta cidade. ${ }^{62}$

Claro está que a indicação de Figueira tem fundamento na sua larga experiência na lida de assuntos referentes ao Estado da Índia e pode muito bem estar relacionada com a marca deixada com o trabalho dos tempos de promotor, talvez mais do que o período de sua atuação como inquisidor de Goa. Mas é importante levar em conta o contexto da criação do Conselho Ultramarino para definirmos melhor o que ocorreu com ele. Para Marcelo Caetano:

o momento da criação do Conselho Ultramarino era fundamental, tratava-se da consolidação do governo de D. João IV diante a vitória sobre os espanhóis. [...] Presidido pelo Marquês de Montalvão, D. Jorge de Mascarenhas, antigo Vice-Rei do Brasil e Vedor da Fazenda em exercício - e posteriormente sempre por fidalgo de primeira nobreza, experimentado nas lides ultramarinas -, compunha-se inicialmente de três conselheiros, dois fidalgos, homens de guerra - Conselheiros de Capa e Espada - e um homem de leis - Conselheiro letrado. Suprimia-se o lugar do canonista, que existia no Conselho da Índia, visto não haver agora matérias eclesiásticas a tratar. ${ }^{63}$

Talvez tenha sido uma tentativa de sinalização de paz por parte do rei de Portugal em relação à Inquisição, pois se sabe que ela não alinhou com o movimento da Restauração, ou apenas era mesmo o prestígio do inquisidor de Goa, Évora e Lisboa que pesara em sua indicação. A despeito de tanta importância e de tão destacado papel, curiosamente, continua a haver um silêncio profundo nas fontes sobre Figueira, o que torna conclusões definitivas impossíveis de serem feitas. No entanto, é extremamente instigante a questão aqui posta.

Foi possível acompanhar alguns despachos feitos por Figueira no Conselho Ultramarino pelo menos até 1651. Antes disso, há uma menção muito rápida que o padre Antônio Vieira faz a Figueira em carta escrita em Haia, de 4 de maio de 1648, “Taquete nos diz que João Delgado Figueira vai a Roma por parte da Inquisição: não sabemos que fundamento tem esta nova, porque de Portugal se não fala em tal cousa", ${ }^{64}$ o que demonstra que era pessoa conhecida e passível de ser envolvida em intrigas palacianas. Além dessas parcas referências, mais nada foi possível localizar, o que, no fundo, surpreende, pois não se trata de personagem sem importância.

Ainda assim, pelo exposto, pode-se dizer que João Delgado Figueira é um caso excepcional e como tal não pode ser visto como a trajetória-padrão de um inquisidor do Santo Ofício de Goa. No entanto, sua carreira de funcionário da Inquisição indica uma série de contradições e constitui-se em um rico veículo para a compreensão dos conflitos entre as instituições da coroa portuguesa existentes no Estado da Índia. Em meio a fontes fragmentárias, o nome desse inquisidor proporcionou um importante fio condutor das reflexões sobre o problema da cristianização de Goa. Mas ainda persiste a dúvida sobre o hiato criado pela campanha violenta de desqualificação de sua função de inquisidor no Oriente e a trajetória ascendente que percorre posteriormente no reino. 
Por fim, o que importa ressaltar é que a partir de fontes diferenciadas e com informações muito fragmentárias, ainda assim, é possível riscar um perfil biográfico de figura instigante para o estudo das instituiçôes portuguesas do século XVII, reforçando assim os argumentos da historiografia para um retorno a biografias. Apesar de conhecerem-se poucos dados da formação de João Delgado Figueira, é possível detectar em seus textos aqui apresentados, a qualidade de sua formação. A partir dos conflitos nos quais se envolveu, percebem-se alguns traços de sua personalidade. Com o caleidoscópio destas pistas documentais, o biografado ganha destaque, especialmente para uma análise do funcionamento das redes de poder nas quais muitos estavam envolvidos no âmbito do reino e domínios portugueses.

\section{Notas}

${ }^{1}$ Lucien Febvre. Erasmo, la contrarreforma y el espiritu moderno. Barcelona: Martinez Roca, 1971, p. 87-96. Utilizei aqui as reflexôes apresentadas em um estudo feito sobre um jesuíta no Oriente, por considerá-las profundamente pertinentes no presente estudo: Célia Cristina da Silva Tavares. Padre Henrique Henriques: modelo de ação cristianizadora na Índia (século XVI). In: Ronaldo Vainfas; Georgina Silva dos Santos; Guilherme Pereira das Neves. (Orgs.). Retratos do Império: trajetórias individuais no mundo português nos séculos XVI a XIX. 1 ed. Niterói: EdUFF, 2006.

${ }^{2}$ Lucien Febvre. Erasmo, la contrarreforma y el espiritu moderno. Barcelona: Martinez Roca, 1971, p. 88 e 91.

${ }^{3}$ Lucien Febvre. Erasmo, la contrarreforma y el espiritu moderno. Barcelona: Martinez Roca, 1971, p. 97-125.

${ }^{4}$ Jacques Le Goff. São Luis: biografia. Rio de Janeiro/São Paulo: Record, 1999, p. 20.

${ }^{5}$ O. Chaussinand-Nogaret. Biographie (Histoire) In: André Burguière (org). Dictionnaire des sciences historiques. Paris: PUF, 1986, p. 86.

${ }^{6}$ Pode-se perceber isso em reflexôes feitas por alguns autores, com destaque para Giovanni Levi. Usos da biografia. In: Marieta de Moraes Ferreira e Janaína Amado (orgs). Usos \& abusos da História Oral. Rio de Janeiro: Editora da FGV, 1996, p. 168; Jacques Le Goff. São Luis: biografia. Rio de Janeiro/São Paulo: Record, 1999. p. 20; Benito Bisso Schimdt. Construindo biografias. Historiadores e Jornalistas: Aproximaçōes e afastamentos. In: Estudo Históricos. Rio de Janeiro, vol. 10, no 19 , 1997, p. 5; José Mattoso. A escrita da História: teoria e métodos. Lisboa: Estampa, 1997, p. 60.

${ }^{7}$ Benito Bisso Schimdt. Construindo biografias. Historiadores e Jornalistas: Aproximaçōes e afastamentos. In: Estudo Históricos. Rio de Janeiro, vol. 10, no 19, 1997, p. 5.

${ }^{8}$ Giovanni Levi. Usos da biografia. In: Marieta de Moraes Ferreira e Janaína Amado (orgs). Usos \& abusos da História Oral. Rio de Janeiro: Editora da FGV, 1996, p. 169.

${ }^{9}$ Pierre Bourdieu. A ilusão biográfica. In: Marieta de Moraes Ferreira e Janaína Amado (orgs). Usos \& abusos da História Oral. Rio de Janeiro: Editora da FGV, 1996, p. 182-183.

${ }^{10}$ Jacques Le Goff. São Luís: biografia. Rio de Janeiro/São Paulo: Record, 1999, p. 20.

${ }^{11}$ Giovanni Levi. Usos da biografia..., p. 167.

${ }^{12}$ José Mattoso. A escrita da História: teoria e métodos. Lisboa: Estampa, 1997, p. 60.

${ }^{13}$ Giovanni Levi. Usos da biografia. In: Marieta de Moraes Ferreira e Janaína Amado (orgs). Usos \& abusos da História Oral. Rio de Janeiro: Editora da FGV, 1996, p. 174-178.

${ }^{14}$ Giovanni Levi. Usos da biografia. In: Marieta de Moraes Ferreira e Janaína Amado (orgs). Usos \& abusos da História Oral. Rio de Janeiro: Editora da FGV, 1996, p. 179-180.

${ }^{15}$ Carlo Ginzburg. A micro-história e outros ensaios. Trad. António Narino Lisboa: Difel, 1991, p. 174.

${ }^{16} \mathrm{Um}$ bom exemplo disso é o estudo desenvolvido por Carla Delgado de Piedade. O contributo português na definição das rotas do Pacífico no século XVI: a viagem de Sebastiāo Rodrigues Soromenho. Dissertação apresentada no Mestrado em História dos descobrimentos e da Expansão Marítima Portuguesa na Faculdade de Letras da Universidade de Lisboa. Lisboa, 2005. A partir da difícil construção da biografia parcial do navegador português Sebastião Rodrigues Soromenho, a autora constrói um interessante painel da participação portuguesa na navegação do Pacífico no século XVI.

${ }^{17}$ Célia Cristina da Silva Tavares. Jesuitas e inquisidores em Goa. Lisboa: Roma Editora, 2004. As reflexôes iniciais sobre a figura de João Delgado Figueira foram consolidadas em um artigo e desde então tenho aprofundado a pesquisa sobre esta personagem, Célia Cristina da Silva Tavares. Esboço de uma biografia do inquisidor João Delgado Figueira. Clio Nova Série Revista do Centro de História da Universidade de Lisboa, Lisboa, v. 9, p. 127-141, 2003.

${ }^{18}$ Francisco Bethencourt. História das Inquisiçôes: Portugal, Espanha e Itália - séculos XV-XIX. São Paulo: Companhia das Letras, 2000, p. 195. 
${ }^{19}$ Para entender a destruição destas fontes leiam-se Antônio Baião. A Inquisição de Goa. Tentativa de história da sua origem, estabelecimento, evolução e extinção. Lisboa: Academia de Ciências, 1945, v. I, p. 15 e José Alberto Rodrigues da Silva. Um inquisidor inquirido: João Delgado Figueira e o seu Reportório, no contexto da "documentação sobre a Inquisição de Goa". In: LEITURAS: Revista da Biblioteca Nacional. Lisboa, no 1, 1997, p. 184.

${ }^{20}$ BNP. Reportório geral de tres mil oito centos processos, que sam todos despachados neste Sancto Officio de Goa, \& mais partes da India do anno de Mil \& quinhentos \& secenta \& hum, que começou o dito Sancto Officio ate o anno de Mil \& seis centos $\&$ vinte e tres cô a lista dos Inquisidores que tem sido nelles $\&$ dos autos publicos da Fee, que se tem celebrado na dita cidade de Goa / feito pelo Licenciado Ioão Delgado Figueyra do Dezembargo de Sua Magestade, Promotor e Deputado do dito Sancto Officio, Sendo Inquisidores os Senhores Francisco Borges de Souza \& Ioão Fernandes de Almeida, 1623. Microfilme F. 2545. A Biblioteca Nacional de Portugal descreve o livro da seguinte forma em seu site: "Trata-se de um repertório alfabético dos autos-de-fé da Inquisição de Goa. - Inclui uma nota final sobre o restabelecimento do tribunal em 1775. - Cada série alfabética tem como "folha de rosto» uma inicial de página inteira, iluminada a cores e ouro. - Folha de rosto iluminada, tendo ao centro a figura de São Pedro mártir (inquisidor dominicano do séc. XIII), com respectivos atributos (cutelo ferindo a cabeça, palma, e a filactera «Credo in Deum», a vermelho); título enquadrado por elementos arquitectónicos e vegetalistas, a cores e ouro; dois anjos tenentes; bustos de São João de Capristano, São Jaime da Marca, São Domingos e São Raimundo. - Contém fólios em branco, não numerados. - Dedicatória ao bispo D. Fernão Martins Mascarenhas (1548-1628), teólogo célebre, reitor da Universidade de Coimbra, cónego da Sé de Évora, bispo do Algarve, inquisidor-geral e conselheiro de Estado, datada de 2 de Janeiro de 1622, Goa. - Encadernado com pastas de cartão revestidas a pele castanha com ferros gravados a ouro". Capturado em site da internet: http://purl.pt/102/1/decoracao/decoracao_thumb_70.html.

${ }^{21}$ Francisco Bethencourt. História das Inquisiçôes: Portugal, Espanha e Itália - séculos XV-XIX. São Paulo: Companhia das Letras, 2000, p. 130.

${ }^{22}$ Francisco Bethencourt. História das Inquisiçôes: Portugal, Espanha e Itália - séculos XV-XIX. São Paulo: Companhia das Letras, 2000, p. 130.

${ }^{23}$ Francisco Bethencourt. História das Inquisiçôes: Portugal, Espanha e Itália- séculos XV-XIX. São Paulo: Companhia das Letras, 2000, p. 195. O autor alerta que não se tratou de um rebaixamento, como à primeira vista pode parecer, mas sim uma manutenção do vínculo com a Inquisição ao ter sido designado "como conselheiro do recém-criado Conselho Ultramarino, uma das mais importantes estruturas do Estado reorganizado depois da revolução de 1640".

${ }^{24}$ BNP. Catálogo dos Inquizidores Geraes, Inquizidores e Deputados das Inquiziçôes de Lx.a, Coimbra e Evora de1720. Microfilme F. 2374.

${ }^{25}$ Segundo Antônio Baião. A Inquisição de Goa. Tentativa de história da sua origem, estabelecimento, evolução e extinção. Lisboa: Academia de Ciências, 1945, v. I, p. 178, no início da Inquisição eram os notários que ofereciam os libelos, depois os deputados assumiram também o papel de promotores, portanto não se fazia distinção destes cargos na Índia.

${ }^{26}$ No período de 1560 a 1682, do total de setenta e seis deputados e promotores nomeados para o tribunal de Goa, sessenta e um pertenciam a ordens religiosas (dominicanos - vinte; jesuítas - dezessete; agostinianos - onze; franciscanos - dez; outras ordens - três); enquanto os outros quinze eram funcionários de tribunais e outras repartições do rei (nove) e do clero secular (seis). Cf. Antônio Baião. A Inquisição de Goa. Tentativa de história da sua origem, estabelecimento, evolução e extinção. Lisboa: Academia de Ciências, 1945, v. I.

${ }^{27}$ José Miguel Ribeiro Lume. Portugueses em cargos, oficios e funçôes no Estado Português da Índia (1580-1640). Contribuição para o seu inventário. Dissertação apresentada no Mestrado em História Moderna da Faculdade de Letras da Universidade de Lisboa. Lisboa, 1994. v. 2. p. 446-448. Baião informa 1626, Lume, 1624.

${ }^{28}$ Cf. Antônio Baião. A Inquisição de Goa. Tentativa de história da sua origem, estabelecimento, evolução e extinção. Lisboa: Academia de Ciências, 1945. v. I. p. 214. Curiosamente das pequenas notas biográficas que Baião apresenta sobre os Inquisidores de Goa do século XVII só o João Delgado Figueira e o Domingos Rebelo Lobo não têm dados pessoais anotados, sem identificação da habilitação. Daí a dificuldade da biografia.

${ }^{29}$ Antônio Baião. A Inquisição de Goa. Tentativa de história da sua origem, estabelecimento, evolução e extinção. Lisboa: Academia de Ciências, 1945, v. I, p. 214.

${ }^{30}$ Antônio Baião. A Inquisição de Goa. Tentativa de história da sua origem, estabelecimento, evolução e extinção. Lisboa: Academia de Ciências, 1945, v. I, p. 215.

${ }^{31}$ Antônio Baião. A Inquisição de Goa. Tentativa de história da sua origem, estabelecimento, evolução e extinção. Lisboa: Academia de Ciências, 1945, v. I, p. 215.

32 Antônio Baião. A Inquisição de Goa. Tentativa de história da sua origem, estabelecimento, evolução e extinção. Lisboa: Academia de Ciências, 1945, v. I, p. 215 e 217.

${ }^{33}$ Antônio Baião. A Inquisição de Goa. Tentativa de história da sua origem, estabelecimento, evolução e extinção. Lisboa: Academia de Ciências, 1945, v. I, p. 217.

${ }^{34}$ Antônio Baião. A Inquisição de Goa. Tentativa de história da sua origem, estabelecimento, evolução e extinção. Lisboa: Academia de Ciências, 1945, v. I, p. 217. 
${ }^{35}$ José Alberto Rodrigues da Silva. Um inquisidor inquirido: João Delgado Figueira e o seu Reportorio, no contexto da "documentação sobre a Inquisição de Goa”. In: LEITURAS: Revista da Biblioteca Nacional. Lisboa, no 1, 1997, p. 186.

${ }^{36}$ ANTT. Conselho Geral do Santo Ofício. Parecer de João Delgado Figueira, promotor e deputado da Inquisição de Goa sobre os sinais gentílicos (1619). Liv. 474.

${ }^{37}$ Roberto Nobili nasceu em Roma no ano de 1577, de uma família nobre de Montepulciano, na Toscana, foi noviço da Companhia de Jesus em Nápoles em 1596. Solicitou aos superiores fazer missão no Oriente, saindo de Lisboa para Índia em 1604, chegando a Goa em 1605. Esteve brevemente em Cochim e na costa da Pescaria. Nobili identificou na casta brâmane a chave das conversōes na Índia, avaliando que se fosse possível cristianizar esse grupo, as outras castas, historicamente submetidas aos brâmanes, os acompanhariam, criando um efeito multiplicador do número de convertidos. Com a autorização dos superiores eclesiásticos, Nobili apresentou-se na região de Maduré, na costa Malabar, em 1606, como um nobre romano que não tinha nenhum vínculo com os outros missionários e com os portugueses e que rejeitara todos os prazeres e confortos do mundo. Adotou a vestimenta amarela dos saniassas, ou seja, assumiu a postura dos brâmanes que viviam o último estágio de sua vida, a completa renúncia. Declarou que seu objetivo era estudar a literatura, as línguas sânscrita e telugu, além da malaiala. Em troca oferecia aos brâmanes da região revelar as verdades do cristianismo. Deixou de comer carne, dedicouse apenas a rezar e a estudar. Dificultava os encontros com os brâmanes, para dar a impressão de sua importância. Nobili gradativamente conseguiu promover a conversão de alguns brâmanes por volta de 1608. Procurava sempre respeitar os costumes indianos que não considerasse superstição. Dessa forma, não reprimia o uso da linha bramânica (tríplice cordão de algodão que os brâmanes traziam a tiracolo da esquerda para direita), do kudumi (tufo na cabeça), o uso do sândalo nas fricçóes corporais, dos banhos rituais, a continuação de sinais na testa que faziam as distinções das castas, entre outros costumes. Em 1610 surgiram as primeiras críticas ao método de Nobili dentro da Companhia de Jesus, que nos anos subseqüentes acabaram por desenvolver um debate amplo, envolvendo as autoridades eclesiásticas de Goa chegando por fim a Roma em 1615.

${ }^{38}$ ANTT. Conselho Geral do Santo Ofício. Liv. 207. Consultas da Inquisição de Goa (1572-1620). fl. 52.

${ }^{39}$ ANTT. Conselho Geral do Santo Ofício. Liv. 207. Consultas da Inquisição de Goa (1572-1620). fl. 61.

${ }^{40}$ ANTT. Conselho Geral do Santo Ofício. Liv. 207. Consultas da Inquisição de Goa (1572-1620). fl. 64.

${ }^{41}$ ANTT. Conselho Geral do Santo Ofício. Liv. 207. Consultas da Inquisição de Goa (1572-1620). fl. 79.

${ }^{42}$ ANTT. Conselho Geral do Santo Ofício. Liv. 207. Consultas da Inquisição de Goa (1572-1620). fl. 83-96.

${ }^{43}$ ANTT. Conselho Geral do Santo Ofício. Liv. 474, Parecer de João Delgado Figueira, promotor e deputado da Inquisição de Goa sobre os sinais gentílicos. Goa, 10 de abril de 1619. 86 fls.

${ }^{44}$ ANTT. Conselho Geral do Santo Ofício. Liv. 207. Consultas da Inquisição de Goa (1572-1620). fl. 98.

${ }^{45}$ ANTT. Conselho Geral do Santo Ofício. Liv. 207. Consultas da Inquisição de Goa (1572-1620). fl. $292-302$.

${ }^{46}$ ANTT. Conselho Geral do Santo Ofício. Livro 101.Consulta do Conselho Geral sobre a prisão que fez Paulo Rebello nas casas do Inquisidor de Goa. 10/01/1631. Lisboa. fl. 2 v-3. O episódio foi narrado pelo próprio inquisidor João Delgado Figueira em carta ao Conselho Geral do Santo Ofício do dia 6 de fevereiro de 1630. Antônio Baião. A Inquisição de Goa. Correspondência dos inquisidores da Índia (1569-1630). Coimbra: Imprensa da Universidade, 1930. v. II. p. 742.

${ }^{47}$ Catarina Madeira Santos. Goa é a chave de toda a Índia. Perfil político da capital do Estado da Índia (1505-1570). Lisboa: Comissão Nacional Para as Comemorações dos Descobrimentos Portugueses, 1999, p. 233.

${ }^{48}$ ANTT. Conselho Geral do Santo Ofício. Livro 101. Consulta do Conselho sobre a lei que o Conde de Linhares publicou sobre a proibição dos palanquins. 10/01/1631. Lisboa. fl. 6 v.

${ }^{49}$ Biblioteca da Ajuda. Miscelânea Coleções de Francisco Barreto. Cartas do Vice-rei da Índia, Conde de Linhares (D. Miguel de Noronha) para o inquisidor em Goa, João Delgado Figueira e resposta do inquisidor. 10 de março de 1630. Códice 51-VI-9. fl. 5.

${ }^{50}$ Biblioteca da Ajuda. Miscelânea Coleçôes de Francisco Barreto. Cartas do Vice-rei da Índia, Conde de Linhares (D. Miguel de Noronha) para o inquisidor em Goa, João Delgado Figueira e resposta do inquisidor. 10 de março de 1630. Códice 51-VI-9. fl. 6.

${ }^{51}$ ANTT. Conselho Geral do Santo Ofício. Liv. 101. Consulta do Conselho sobre a junta que o Conde de Linhares fez a que chamou o inquisidor João Delgado e ele não foi. Lisboa. 13/11/1631.

${ }^{52}$ José Alberto Rodrigues da Silva. Um inquisidor inquirido: João Delgado Figueira e o seu Reportorio, no contexto da "documentação sobre a Inquisição de Goa”. In: LEITURAS: Revista da Biblioteca Nacional. Lisboa, no 1, 1997, p. 186.

${ }^{53} \mathrm{O}$ texto da visitação encontra-se no ANTT. Conselho Geral do Santo Ofício. Visita a Inquisição de Goa de D. Francisco de Castro. Liv. 184. Mas não há as conclusões finais do Conselho Geral nessa documentação.

${ }^{54}$ É interessante lembrar que o jesuíta Antônio de Andrade era uma figura de grande destaque na Companhia de Jesus. Nascido em Oleiros, Castelo Branco, Portugal, no ano de 1580, foi admitido ao noviciado em 1596, partindo para a Índia em 1600. Em Goa completou a formação religiosa e, em seguida, foi enviado a Agra, como superior e visitador da missão mogol. Ali reuniu informações sobre o Tibete e decidiu empreender uma viagem para essa região. Em 1624 iniciou a jornada, 
conseguindo superar as dificuldades do Himalaia e localizando as nascentes do rio Ganges. Chegou enfim ao reino de Guge, e obteve permissão do rei local para pregar a fé católica. Retornando a Agra, informou por carta ao visitador da Companhia de Jesus na Índia, André Palmeiro, sobre a sua ousada viagem, e em 1625 voltou ao Tibete, onde conseguiu a conversão do rei e da rainha de Guge, entre outros habitantes locais. Em 1629 foi chamado a Goa para assumir o cargo de provincial e depois o de reitor, além de ter assumido o cargo de deputado da Inquisição de Goa, em 1633. Preparava-se para voltar ao Tibete quando foi envenenado por um irmão jesuíta. Para maior aprofundamento ver Hugues Didier (org). Les portugais au Tibet: les premières relations jésuites (1624-1635). Paris: Editions Chandeigne, 1996.

${ }^{55}$ ANTT. Conselho Geral do Santo Ofício. Visita a Inquisição de Goa de D. Francisco de Castro (1632-1633). Liv. 184. fl. $1-2 \mathrm{v}$.

${ }^{56}$ ANTT. Conselho Geral do Santo Ofício. Visita a Inquisição de Goa de D. Francisco de Castro (1632-1633). Liv. 184. fl. 5.

${ }^{57}$ ANTT. Conselho Geral do Santo Ofício. Visita a Inquisição de Goa de D. Francisco de Castro (1632-1633). Liv. 184. fl. 6-8 v. Note-se que nesse trecho há uma clara rivalidade entre os inquisidores. Isso parece ser algo comum, se basear-nos em uma carta de 1595 do Conselho Geral do Santo Ofício aos inquisidores de Goa, ordenando que não houvesse diferenças particulares entre eles. BNRJ. Inquisição de Goa. 25, 2, $1 \mathrm{n}$ os 212-213.

${ }^{58}$ ANTT. Conselho Geral do Santo Ofício. Visita a Inquisição de Goa de D. Francisco de Castro (1632-1633). Liv. 184. fl. 20-25 v.

${ }^{59}$ Francisco Bethencourt. História das Inquisiçôes: Portugal, Espanha e Itália - séculos XV-XIX. São Paulo: Companhia das Letras, 2000, p. 194-195.

${ }^{60}$ Antônio Baião. A Inquisição de Goa. Tentativa de história da sua origem, estabelecimento, evolução e extinção. Lisboa: Academia de Ciências, 1945, v. 1, p. 329, também se coloca em dúvida sobre a veracidade das acusações e depoimentos arrolados pela visita de 1632 .

${ }^{61}$ Antônio Baião. A Inquisição de Goa. Tentativa de história da sua origem, estabelecimento, evolução e extinção. Lisboa: Academia de Ciências, 1945, v. 1, p. 218.

${ }^{62}$ Ana Rita Amaro Monteiro. Legislação e Actos de Posse do Conselho Ultramarino (1642-1830). Edição Paleográfica. Porto: Universidade Portucalense, 1997, p. 35.

${ }^{63}$ Marcelo Caetano. O Conselho Ultramarino: esboço da sua história. Lisboa: Agência Geral do Ultramar, 1967, p. 42-3.

${ }^{64}$ João Adolfo Hansen (org). Cartas do Brasil: 1626-1697. Estado do Brasil e Estado do Maranhão e Grão-Pará por António Vieira. São Paulo: Hedra, 2003, p 389.

\section{Referências bibliográficas}

BAIÃO, Antônio. A Inquisição de Goa. Tentativa de história da sua origem, estabelecimento, evolução e extinção. Lisboa: Academia de Ciências, 1945, 2 v.

BETHENCOURT, Francisco. História das Inquisiçôes: Portugal, Espanha e Itália - séculos XV-XIX. São Paulo: Companhia das Letras, 2000.

BOURDIEU, Pierre. A ilusão biográfica. In: FERREIRA, Marieta de Moraes \& AMADO, Janaína (Orgs). Usos \& abusos da História Oral. Rio de Janeiro: Editora da FGV, 1996.

CAETANO, Marcelo. O Conselho Ultramarino: esboço da sua história. Lisboa: Agência Geral do Ultramar, 1967. CHAUSSINAND-NOGARET, O. Biographie (Histoire). In: BURGUIÈRE, André (Org). Dictionnaire des sciences historiques. Paris: PUF, 1986.

DIDIER, Hugues (Org). Les portugais au Tibet: les premières relations jésuites (1624-1635). Paris: Editions Chandeigne, 1996.

FEBVRE, Lucien. Erasmo, la contrarreforma y el espiritu moderno. Barcelona: Martinez Roca, 1971.

GINZBURG, Carlo. A micro-história e outros ensaios. Trad. António Narino Lisboa: Difel, 1991.

HANSEN, João Adolfo (Org). Cartas do Brasil: 1626-1697. Estado do Brasil e Estado do Maranhão e Grã Pará por António Vieira. São Paulo: Hedra, 2003.

LE GOFF, Jacques. São Luis: biografia. Rio de Janeiro/São Paulo: Record, 1999.

LEVI, Giovanni. Usos da biografia. In: FERREIRA, Marieta de Moraes \& Amado, Janaína (Orgs). Usos \& abusos da História Oral. Rio de Janeiro: Editora da FGV, 1996.

LUME, José Miguel Ribeiro. Portugueses em cargos, oficios e funçôes no Estado Português da Índia (1580-1640). Contribuição para o seu inventário. Dissertação apresentada no Mestrado em História Moderna da Faculdade de Letras da Universidade de Lisboa. Lisboa, 1994, 2 v. 
MATTOSO, José. A escrita da História: teoria e métodos. Lisboa: Estampa, 1997.

MONTEIRO, Ana Rita Amaro. Legislação e Actos de Posse do Conselho Ultramarino (1642-1830). Edição Paleográfica. Porto: Universidade Portucalense, 1997.

PATRIARCA, Raquel. Um estudo sobre a Inquisiçāo de Lisboa: o Santo Oficio na Vila de Setúbal-1536-1650. Dissertação de Mestrado em História Moderna apresentado à Faculdade de Letras da Universidade do Porto, Porto, 2002.

PIEDADE, Carla Delgado de. O contributo português na definição das rotas do Pacifico no século XVI: a viagem de Sebastiāo Rodrigues Soromenho. Dissertação apresentada no Mestrado em História dos descobrimentos e da Expansão Marítma Portuguesa na Faculdade de Letras da Universidade de Lisboa. Lisboa, 2005.

SANTOS, Catarina Madeira. Goa é a chave de toda a Índia. Perfil político da capital do Estado da Índia (15051570). Lisboa: Comissão Nacional Para as Comemorações dos Descobrimentos Portugueses, 1999.

SCHIMDT, Benito Bisso. Construindo biografias. Historiadores e Jornalistas: Aproximações e afastamentos. Estudo Históricos. Rio de Janeiro, v. 10, no 19, 1997.

TAVARES, Célia Cristina da Silva. Jesuitas e inquisidores em Goa. Lisboa: Roma Editora, 2004.

. Padre Henrique Henriques: modelo de ação cristianizadora na Índia (século XVI). In: VAINFAS, Ronaldo; SANTOS, Georgina Silva dos; NEVES, Guilherme Pereira das (Orgs.). Retratos do Império: trajetórias individuais no mundo português nos séculos XVI a XIX. 1ํㅡㄹ ed. Niterói: EdUFF, 2006.

. Esboço de uma biografia do inquisidor João Delgado Figueira. Clio Nova Série Revista do Centro de História da Universidade de Lisboa, Lisboa, v. 9, p. 127-141, 2003.

TAVIM, José Alberto Rodrigues da Silva. Um inquisidor inquirido: João Delgado Figueira e o seu Reportorio, no contexto da "documentação sobre a Inquisição de Goa". LEITURAS: Revista da Biblioteca Nacional. Lisboa, no 1 , p. 183-193, 1997.

\section{RESUMO}

O presente artigo pretende analisar a possibilidade de realização da biografia de um inquisidor de Goa, João Delgado Figueira, a partir da documentação produzida pela própria Inquisição que investigava acusaçôes de práticas desaconselhadas feitas por este funcionário. Apesar de ser figura importante, tendo sido inquisidor nos tribunais de Goa, Évora e Lisboa, além de membro do primeiro Conselho Ultramarino, existem muito poucas informaçôes consolidadas por esta figura histórica. Se, por um lado, ele foi acusado de administrar mal as coisas do Santo Oficio, por outro existe um bem registrado esforço de organização do Tribunal de Goa por parte de João Delgado Figueira, na época quando era promotor e deputado do mesmo tribunal. Assim, uma leitura da documentação inquisitorial proporciona a análise do perfil contraditório desta personagem.

Palavras-chave: Inquisição de Goa, João Delgado Figueira, biografia.

\section{ABSTRACT}

This article aims to examine the biography of an inquisitor of Goa, João Delgado Figueira, from the documentation produced by the Portuguese Inquisition that was investigating allegations of bad practices made by this official. Despite being an important figure, was inquisitor in the courts of Inquisitions of Goa, Evora and Lisbon, and member of the first Conselho Ultramarino, there is very little consolidated information about this historical figure. If, on the one hand, he was accused of mismanaging the things of the Holy Office, on the other there is a well documented organizational effort of the Inquisition of Goa by João Delgado Figueira. Thus a reading of the documentation provides the inquisitorial profile analysis of this contradictory character.

Keywords: Inquisition of Goa, João Delgado Figueira, biography. 